\title{
O óleo de abacate (Persea americana Mill) como matéria-prima para a indústria alimentícia
}

\author{
The avocado oil (Persea americana Mill) as a raw material for the food industry \\ Jocelem Mastrodi SALGADO ${ }^{1 *}$, Flávia DANIELI ${ }^{1}$, Marisa Aparecisa Bismara REGITANO-D’ARCE \\ Andrea FRIAS ${ }^{1}$, Débora Niero MANSI ${ }^{2}$
}

\begin{abstract}
Resumo
Hábitos de vida saudáveis e uma dieta balanceada aliados ao alto consumo de frutas e vegetais estão associados à redução do risco de doenças e à manutenção da saúde. O óleo de abacate possui em sua composição substâncias bioativas capazes de prevenir e controlar as dislipidemias. Como existem poucas pesquisas científicas avaliando o potencial deste óleo para o consumo humano, o presente trabalho estudou os processos de extração e refino do óleo de abacate. Para tanto, procedeu-se à separação da polpa das outras partes da fruta. A polpa fresca foi seca em estufa, e posteriormente moída para a obtenção de um farelo. O óleo obtido do farelo foi extraído e caracterizado. Os resultados mostraram que os processos de extração e refino do óleo a partir da variedade Margarida são tecnicamente viáveis, o que o torna excelente matériaprima para a indústria alimentícia. Além disso, possui um perfil de ácidos graxos e esteróis muito semelhante ao perfil do azeite de oliva, podendo desta forma, substituir o óleo de soja e ser utilizado juntamente com o azeite de oliva nos óleos mistos, oferecendo ao consumidor brasileiro um produto de qualidade superior e com menor custo.

Palavras-chave: óleo de abacate; colesterol; esteróis vegetais; vitamina E.
\end{abstract}

\begin{abstract}
Healthy life habits and an adequate diet, together with a high intake of fruits and vegetables, are associated with reducing the risk of diseases and maintaining health. The avocado oil has bioactive substances that can prevent and control the hyperlipidemia. Since there is little scientific research evaluating the oil potential for human consumption, the present work studied the extraction and refining process of the avocado oil. Firstly, the pulp was extracted from the fruit. The fresh pulp was dried in a stove and then grounded for obtaining the bran. The oil obtained from de bran was extracted and characterized. The results showed that the extraction and refining process of the Margarida avocado variety is technically feasible, and it is an excellent raw material for the food industry. Besides, the fatty acid composition and the sterols presents in the avocado oil are similar to the olive oil. Thus, the avocado oil can substitute the soybean oil, or it can be mixed with the olive oil offering the Brazilian consumers a product of high quality and low cost.

Keywords: avocado oil; cholesterol; sterols; vitamin E; oleic acid.
\end{abstract}

\section{Introdução}

A doença cardiovascular é a principal causa de morbimortalidade no Brasil (300.000 mortes/ano), representando um enorme ônus financeiro para o país (CORONELLI; MOURA, 2003).

Alguns estudos populacionais chamam a atenção para uma maior suscetibilidade às doenças crônicas em grupos submetidos à modernização do seu estilo de vida. Mudanças na dieta, estresse psicológico, sedentarismo, obesidade, hereditariedade e mudanças sócio-econômicas têm sido considerados fatores de risco para essa situação (CARDOSO; MATTOS; KOIFMAN, 2001).

Quanto maior a intensidade e o tempo de exposição ao fator de risco, maior a possibilidade de desenvolver a doença. A hipercolesterolemia é um importante fator de risco para doenças cardiovasculares.
De acordo com dados da American Hearth Association (2002), mais de $30 \%$ da população brasileira e $51 \%$ da população americana apresentam altos níveis de colesterol (maior que $\left.200 \mathrm{mg} \cdot \mathrm{dL}^{-1}\right)$, sendo este um dado preocupante, já que estudos mostram que taxas acima de $240 \mathrm{mg} \cdot \mathrm{dL}^{-1}$ de colesterol total duplicam o risco de um indivíduo sofrer um ataque cardíaco.

A literatura aponta para o início da aterosclerose já na infância, pelo aumento do colesterol plasmático, que pode ser potencializado no decorrer da vida pelo tabagismo, sedentarismo, hipertensão arterial, obesidade e, principalmente, alimentação inadequada (CARDOSO; MATTOS; KOIFMAN, 2001).

No Brasil, Gerber e Zielinsky (1997) encontraram 28\% de hipercolesterolemia em crianças de 6 a 14 anos, residentes em Bento Gonçalves, Rio Grande do Sul. Um outro estudo realizado em Campinas, por Moura et al. (2000), mostrou

${ }^{1}$ Alimentos e Nutrição/Nutrição Humana e Alimentos, Escola Superior de Agricultura Luiz de Queiroz - ESALQ, Universidade de São Paulo - USP, CEP 13418-900, Piracicaba - SP, Brasil, E-mail: jmsalgad@esalq.usp.br

${ }^{2}$ Faculdade de Engenharia de Alimentos, Universidade Estadual de Campinas - UNICAMP, Campinas - SP, Brasil

${ }^{*}$ A quem a correspondência deve ser enviada 
15,7\% de hipercolesterolemia leve, 9,8\% de moderada e 9,5\% de grave, totalizando $35 \%$ dos escolares com algum nível de hipercolesterolemia.

O controle das doenças cardiovasculares pode ser feito com o auxílio de medicamentos ou através da dieta, que consiste também na melhor forma de prevenção. Recomendações recentes sugerem que o consumo de grãos, frutas e vegetais deve ser aumentado para se prevenir ou tratar essas doenças (COMMITTEE ON DIET AND HEALTH, 1989), e dentre os possíveis componentes destes alimentos que teriam ações hipocolesterolêmicas destacam-se as proteínas vegetais, as fibras e alguns compostos fitoquímicos como os esteróis/estanóis, ácido fítico, taninos, inibidores de enzimas, saponinas, entre outros.

Entre os alimentos fontes dessas substâncias, o óleo de abacate se destaca pela excelente qualidade nutricional. De acordo com alguns estudos, o óleo é rico em $\beta$-sitosterol e ácido oléico, uma gordura insaturada utilizada como coadjuvante no tratamento de hiperlipidemias.

Além disso, assemelha-se muito com o óleo de oliva (importado e altamente consumido no país), por ser extraído da polpa dos frutos e pela similaridade de suas propriedades físico-químicas, principalmente pela composição de seus ácidos graxos, predominando em ambos o ácido oléico (TANGO; CARVALHO; LIMONTA, 2004).

Além da possibilidade de introduzir o óleo de abacate puro para uso comestível como substituto do óleo de oliva, uma das alternativas para oferecer ao consumidor brasileiro um produto de qualidade superior seria a produção de óleo de oliva e abacate mesclado, em substituição às misturas de óleo de oliva com óleos vegetais (principalmente óleo de soja), normalmente oferecidas pelo mercado interno com a finalidade de diminuir os custos de importação do azeite de oliva no Brasil (SOARES; MANCINI FILHO; DELLA MODESTA, 1998).

Com base no exposto acima e na procura dos consumidores por alimentos mais saudáveis, que possam ser utilizados como coadjuvantes no tratamento de algumas doenças, o presente trabalho teve como objetivo desenvolver e traçar um perfil qualitativo e funcional do óleo de abacate, para ser utilizado como matéria-prima na indústria alimentícia; estudar os processos de extração e refino do óleo de abacate da variedade Margarida; avaliar as características físico-químicas do óleo bruto e semirefinado e quantificar as substâncias com ação funcional no óleo bruto e semi-refinado.

\section{Material e métodos}

O experimento foi realizado nos Laboratórios de Bromatologia e Óleos e Gorduras do Departamento de Agroindústria, Alimentos e Nutrição da Escola Superior de Agricultura "Luiz de Queiroz" - ESALQ/USP.

Foram utilizados frutos de abacate da variedade Margarida, provenientes da região de Piracicaba - SP. Os abacates foram colhidos no seu estado de maturação quando ainda se apresentavam firmes. Logo após foram armazenados à temperatura ambiente, até atingirem seu ponto de maturação, ou seja, quando os frutos amolecem e cedem à leve pressão feita com os dedos.
A variedade Margarida foi selecionada por encontrar-se facilmente disponível no mercado brasileiro e apresentar teor de matéria graxa ao redor de $20 \%$.

Para extração do óleo foi utilizado o abacate no seu ponto de maturação, pois segundo alguns autores como Montenegro (1961), o teor de óleo na polpa do abacate eleva-se progressivamente desde o início de formação do fruto até a sua maturação.

\subsection{Caracterização da matéria-prima}

Para caracterização da matéria-prima foi colhida, ao acaso, uma amostra de 35 frutos, que foram pesados e separados nos seus três componentes: casca, polpa e caroço. Nesse material foram determinados o peso médio e a porcentagem da casca, polpa e caroço.

\subsection{Composição centesimal da polpa de abacate}

A polpa de abacate fresca foi caracterizada por métodos físico-químicos, segundo metodologia oficial da AOAC (1984), através da determinação dos teores de umidade, proteínas, lipídios, fibra bruta, cinzas e carboidratos totais.

\subsection{Extração do óleo bruto}

Inicialmente, procedeu-se a separação da polpa fresca das outras partes da fruta. Em seguida, a polpa foi seca em estufa a $50{ }^{\circ} \mathrm{C}$ e moída para a obtenção de um farelo.

O óleo bruto do farelo foi extraído pelo processo de extração por solvente em extrator tipo soxhlet, sendo realizados dois ensaios: um com hexano e acetona na proporção 1:1 e outro somente com o hexano. Posteriormente, o solvente foi evaporado em evaporador rotativo, obtendo-se o óleo bruto.

O fluxograma do processo de extração é apresentado na Figura 1.

\subsection{Neutralização do óleo bruto}

A partir do óleo bruto, foram realizados ensaios de neutralização, com soluções de soda em diferentes concentrações: 15, 20, 25, 30 e $35^{\circ}$ Bē (Graus Beumē). Para cada concentração de soda testada, observou-se a floculação (formação de flocos) e sua sedimentação.

\subsection{Caracterização química dos óleos bruto e neutralizado}

O óleo bruto e o neutralizado foram caracterizados através de metodologia oficial quanto a:

- Teor de ácidos graxos livres e índice de acidez: método Ca 5a-40 AOCS (1995);

- Índice de iodo: método Cd 1b-87 AOCS (1990);

- Índice de peróxido: método Cd 8-53 AOCS (1983);

- Índice de saponificação: método Cd3-25 AOCS (1995);

- Matéria insaponificável: método proposto por Hartman e Esteves (1982); e 
- Composição em ácidos graxos: determinada após conversão dos mesmos em ésteres metílicos, e analisados por cromatografia gasosa, empregando-se cromatógrafo a gás da marca Agilent 6850 Series-GC System, com injetor automático acoplado ao detector FID, com software Agillent Chemstation Plus, version A.08xx para integração e registro do cromatograma, utilizando coluna capilar DB-23 AGILENT (50\% cianopropil - metilpolisiloxane, $60 \mathrm{~m}$, $0,25 \mathrm{~mm}$ de diâmetro interno, $0,25 \mu \mathrm{m}$ de espessura de filme). Condições de operação do cromatógrafo: fluxo coluna $=1,0 \mathrm{~mL} /$ minuto; velocidade linear $=24 \mathrm{~cm} /$ segundo; temperatura do detector $=280^{\circ} \mathrm{C}$; temperatura do injetor $=250^{\circ} \mathrm{C}$; temperatura de forno $=110^{\circ} \mathrm{C}-5$ minutos, $110-215^{\circ} \mathrm{C}\left(5^{\circ} \mathrm{C} /\right.$ minuto $), 215^{\circ} \mathrm{C}-24$ minutos; gás de arraste $=$ Hélio; volume injetado $=1,0 \mu \mathrm{L}$.

A identificação dos ácidos graxos foi efetuada através da comparação de tempo de retenção de padrões injetados nas mesmas condições que a amostra.

Composição de esteróis totais: determinada mediante cromatografia em fase gasosa, empregando-se cromatógrafo a gás da marca Agilent 6850 Series-GC System, com injetor automático acoplado a detector FID, com software Agillent Chemstation Plus, version A.08xx para integração e registro do cromatograma, utilizando coluna capilar de sílica fundida LM 5 ( $5 \%$ fenil $95 \%$ metilpolisiloxane, $30 \mathrm{~m}, 0,25 \mathrm{~mm}$ de diâmetro interno, $0,3 \mu \mathrm{m}$ de espessura de filme).

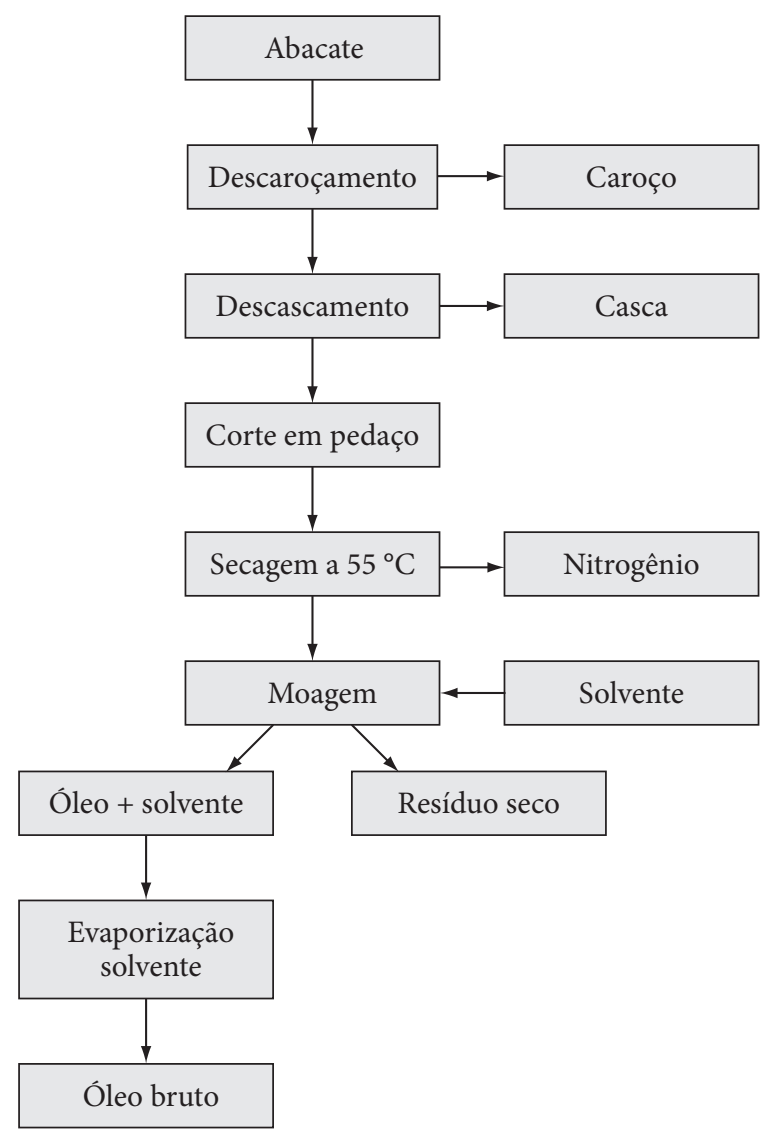

Figura 1. Fluxograma do processo de extração.
Utilizou-se sílica gel 60 (Merck) para confecção das cromatoplacas de vidro preparativas de $20 \times 20 \mathrm{~cm}$, solução etanólica de 2,7 - diclorofluoresceína a 0,2\% como revelador e os componentes da matéria insaponificável foram visualizados em cabine com lâmpada ultravioleta a $365 \mathrm{~nm}$ ("Original Hanau" $220 \mathrm{~V}, 50 \mathrm{~Hz} 85 \mathrm{~W}$ ).

Padrões cromatográficos: $\beta$-sitosterol $=60 \%$ de pureza (Sigma, S-5753); Campesterol (Sigma, C-5157); Estigmasterol (Fluka, 85860); padrão interno (PI) Dihidrocolesterol $(5 \alpha$-cholestan-3 $\beta$-ol; âcholestanol $)=95-97 \%$ de pureza (Sigma, D-6128); Colesterol (5-cholesten-3 $\beta$-ol) $=99 \%$ de pureza (Sigma, C-8667).

Condições cromatográficas: Temperaturas do injetor, forno e detector de 280,300 e $300{ }^{\circ} \mathrm{C}$, respectivamente; fluxo de Hélio de $1,1 \mathrm{~mL} /$ minuto; pressão na coluna $=25,86$ psi; velocidade média $=35 \mathrm{~cm} /$ segundo; hidrogênio $=30 \mathrm{~mL} /$ minuto; ar $=300 \mathrm{~mL} /$ minuto; make up $(\mathrm{N} 2)=20 \mathrm{~mL} /$ minuto; split $=50: 1$; volume de injeção $=1 \mu \mathrm{L}$ e tempo de corrida $=30$ minutos.

Vitamina E: a determinação da concentração de tocoferol no óleo de abacate foi realizada através da referência AOCS Ce 8-89. Posteriormente, as amostras foram injetadas no aparelho de cromatografia líquida de alta eficiência com um loop de $20 \mu \mathrm{L}$, tendo como fase móvel hexano e isopropanol $(98,8 / 1,2)$ com fluxo de $0,6 \mathrm{~mL}$ por minuto.

\section{Resultados e discussão}

\subsection{Caracterização da matéria-prima}

Pela pesagem de 35 frutos determinou-se um peso médio de 607 g. Na Tabela 1 são mostrados os valores correspondentes à proporção dos componentes: casca, polpa e caroço do fruto. Na Tabela 2 encontram-se os resultados da composição centesimal da polpa.

De acordo com Medina (1978), a época de colheita tem influência na composição dos frutos. Os frutos colhidos 30 dias antes da época considerada normal para a colheita possuem maiores proporções de casca e caroço e menor porcentagem de polpa. Apresentam também menores porcentagens de matéria graxa e teores mais elevados de água na polpa. Pelos resultados presentes na Tabela 1, verifica-se que os abacates foram colhidos na época correta de maturação, proporcionando maior rendimento na extração do óleo.

Relacionando os resultados, também verifica-se que o teor de óleo do abacate está concentrado na polpa e, sendo esta o principal componente da fruta (66\%), pode-se confirmar que a variedade Margarida se constitui uma importante matériaprima para a extração do óleo.

Quanto aos demais componentes presentes na polpa, ressalta-se o valor reduzido em proteínas e um alto teor de fibras.

Tabela 1. Proporção de casca, polpa e caroço presentes no fruto do abacate da variedade Margarida.

\begin{tabular}{cccc}
\hline & \multicolumn{3}{c}{ Componentes do fruto } \\
\cline { 2 - 4 } & Casca & Polpa & Caroço \\
\hline Proporção (\%) & 11,2 & 66,0 & 22,8 \\
\hline
\end{tabular}


Alguns estudos relacionam as fibras com a prevenção de certas enfermidades como diverticulite, câncer de cólon, obesidade, problemas cardiovasculares e diabetes. Além disso, o alto teor de fibras permite que o farelo resultante da extração do óleo possa ser utilizado na elaboração de produtos de panificação (biscoitos e pães) e massas alimentícias, ampliando a oferta de produtos ricos em fibras (ARTZ et al., 1990; EL-DASH; GERMANI, 1994; JELTEMA; ZABIK; THIEL, 1983; JORGE, et al., 1998).

\subsection{Extração do óleo bruto}

O óleo bruto, extraído no primeiro ensaio com hexano e cetona (1:1), apresentou uma coloração verde intensa, porém, límpida, além de odor característico e sabor amargo. Já o óleo extraído no segundo ensaio somente com hexano solidificou-se, apresentando características de pomada, à temperatura ambiente.

\subsection{Neutralização do óleo bruto}

Na Tabela 3 encontram-se os resultados do teste de neutralização do óleo bruto de abacate com soluções de soda em diferentes concentrações.

A partir da concentração de $30^{\circ} \mathrm{Bē}\left(23,67 \mathrm{~g} \mathrm{NaOH} .100 \mathrm{~g}^{-1}\right)$ se obteve uma floculação mais rápida e firme, sem formação de emulsão e com boa sedimentação da borra (sabão). Nos ensaios com baixa concentração de soda, houve pouca formação de flocos de sabão, sendo estes de tamanho muito pequeno. $\mathrm{Na}$ concentração mais alta, houve saponificação do óleo, o que dificultou a separação da borra do óleo neutro.

\subsection{Caracterização química dos óleos bruto e neutralizado}

Na Tabela 4 são mostrados os resultados da análise de ácidos graxos por cromatografia do óleo bruto extraído por solvente, bem como as especificações do mercado internacional de óleo

Tabela 2. Composição centesimal da polpa de abacate da variedade Margarida.

\begin{tabular}{lr}
\hline \multicolumn{1}{c}{ Determinações } & Polpa \\
\hline Umidade (\%) & 58,35 \\
Proteína (N x 6,25) (\%) & 2,54 \\
Matéria graxa (\%) & 26,31 \\
Fibras (\%) & 4,85 \\
Cinzas (\%) & 0,60 \\
Carboidratos (\%) & 7,25 \\
\hline
\end{tabular}

Tabela 3. Resultados do teste de neutralização do óleo bruto de abacate, variedade Margarida, com soluções de hidróxido de sódio em diferentes concentrações.

\begin{tabular}{|c|c|c|c|}
\hline \multirow[t]{2}{*}{ Amostra } & \multicolumn{2}{|c|}{$\begin{array}{c}\text { Solução de } \\
\mathrm{NaOH}\end{array}$} & \multirow[t]{2}{*}{$\begin{array}{c}\text { Formação de sabão (floculação) } \\
\text { e sedimentação }\end{array}$} \\
\hline & ${ }^{\circ} \mathrm{B} \overline{\mathrm{e}}$ & $\% \mathrm{NaOH}$ & \\
\hline 1 & 15 & 10,06 & Não formou flocos \\
\hline 2 & 20 & 14,37 & Não formou flocos \\
\hline 3 & 25 & 18,58 & Flocos pequenos - pequena sedimentação \\
\hline 4 & 30 & 23,67 & Flocos firmes - boa sedimentação \\
\hline 5 & 35 & 28,83 & Saponificação do óleo neutro \\
\hline
\end{tabular}

bruto de abacate e a composição de ácidos graxos do óleo da polpa de diferentes variedades de abacate.

De acordo com os dados da tabela, verifica-se que o óleo da variedade Margarida contém uma quantidade menor de ácido oléico quando comparado aos óleos extraídos das variedades Wagner, Fuerte e Quintal, mas encontra-se dentro dos limites do padrão internacional. De acordo com Medina (1978), isso acontece quando o abacate é colhido até 30 dias antes da colheita normal.

Já a quantidade dos ácidos linoléico e linolênico no óleo da variedade Margarida é bem maior em relação aos óleos das outras variedades.

Na Tabela 5 foi feita uma comparação entre a composição de ácidos graxos do óleo da variedade Margarida com o azeite de oliva. Nota-se que o óleo de abacate caracteriza-se pela alta porcentagem de ácido oléico e, por esse motivo, assemelha-se muito com $\mathrm{o}$ azeite de oliva (TANGO; CARVALHO; LIMONTA, 2004).

Os óleos bruto e neutralizado apresentaram as características químicas encontradas na Tabela 6.

Os resultados das características químicas dos óleos bruto e neutralizado estão em conformidade com os resultados encontrados por Medina (1978), com exceção do índice de iodo. Ainda de acordo com Medina (1978), os teores de ácidos graxos livres e matéria insaponificável, assim como os índices de iodo e saponificação variam de acordo com as cultivares e dentro de uma mesma variedade também são influenciados pelas localidades de cultura e pelas condições climáticas do ano agrícola. Por isso, essa diferença se deve à utilização de variedades de abacate diferentes, pois em alguns experimentos foi utilizada a variedade Fuerte e em outros, variedades de origem africana. Já os óleos brutos obtidos possuíram teores de acidez variável entre 0,4 e 1,3\% de ácidos graxos livres. Os valores de matéria insaponificável encontrados nos óleos situaram-se entre 1,2 e $4,7 \%$ e a variação nos índices de saponificação situaram-se entre 176 e 190 mg de KOH.g-g de amostra.

Quando os resultados da caracterização química do óleo bruto foram comparados com o padrão internacional para óleo bruto de abacate, notou-se que o índice de peróxido estava acima do máximo permitido, que é de $5,0 \mathrm{meq} \mathrm{O}_{2} \cdot \mathrm{kg}^{-1}$ de amostra. Entretanto, quando se compara o resultado do índice de peróxido do óleo já neutralizado com a Resolução RDC nº 270 da ANVISA (2005), que estabelece o regulamento técnico para óleos vegetais, verifica-se que esse valor encontra-se dentro do limite permitido, que é de no máximo $10 \mathrm{meq} \mathrm{O}_{2} \cdot \mathrm{kg}^{-1} \mathrm{de}$ amostra, para óleos vegetais semi-refinados. Importante salientar que a resolução da ANVISA (2005) não faz nenhuma alegação para o óleo de abacate, já que esse produto não é comercializado no Brasil. Mas esse valor é permitido para óleos semi-refinados e se aplica a todos os óleos comestíveis do país. Além disso, esse resultado demonstra que durante a extração houve poucas alterações oxidativas.

A Tabela 7 apresenta a composição de esteróis do óleo da variedade Margarida, comparado com a composição de esteróis dos óleos das variedades Fuerte e Waldin. Ressalta-se que o óleo da variedade Margarida destaca-se pelo seu alto teor de 
Tabela 4. Composição em ácidos graxos do óleo bruto de abacate, da variedade Margarida, comparado com as especificações do mercado internacional de óleo bruto de abacate e resultados da composição de diferentes variedades de abacate.

\begin{tabular}{lcccrr}
\hline Ácidos graxos (\%) & $\begin{array}{c}\text { Óleo da variedade } \\
\text { Margarida }\end{array}$ & Padrão internacional & $\begin{array}{c}\text { Óleo da variedade } \\
\text { Wagner }\end{array}$ & $\begin{array}{c}\text { Óleo da variedade } \\
\text { Quintal }\end{array}$ & $\begin{array}{c}\text { Óleo da variedade } \\
\text { Fuerte }\end{array}$ \\
\hline Mirístico & 0,13 & Max 1,0 & 0,02 & - & 0,04 \\
Palmítico & 22,74 & Max 13,0 & 20,53 & 19,86 & 20,84 \\
Palmitoléico & 3,92 & Max 3,5 & 4,64 & 4,20 & 5,63 \\
Esteárico & 1,07 & Max 1,0 & 0,50 & 0,86 & 0,69 \\
Oléico & 55,81 & Max 78,0 & 66,47 & 66,20 & 62,99 \\
Linoléico & 15,30 & Max 12,0 & 7,09 & 8,85 & 9,35 \\
Linolênico & 1,03 & Max 1,0 & 0,79 & - & 0,37 \\
\hline
\end{tabular}

Tabela 5. Comparação entre a composição de ácidos graxos do óleo de abacate da variedade Margarida e o azeite de oliva.

\begin{tabular}{lcc}
\hline Ácidos graxos (\%) & $\begin{array}{c}\text { Óleo de abacate variedade } \\
\text { Margarida }\end{array}$ & ${ }^{*}$ Azeite de oliva \\
\hline Mirístico & 0,13 & - \\
Palmítico & 22,74 & 10,8 \\
Palmitoléico & 3,92 & - \\
Esteárico & 1,07 & 3,8 \\
Oléico & 55,81 & 69,5 \\
Linoléico & 15,30 & 14,9 \\
Linolênico & 1,03 & 0,6 \\
\hline
\end{tabular}

${ }^{*}$ Fonte: USDA National Nutrient Database for Standard Reference (UNITED STATE DEPARTMENT OF AGRICULTURE, 2005).

Tabela 6. Caracterização química do óleo bruto e do óleo neutralizado de abacate da variedade Margarida.

\begin{tabular}{lcc}
\hline \multicolumn{1}{c}{ Determinações } & Óleo bruto & Óleo neutralizado \\
\hline \% AGL & 0,91 & 0,36 \\
Índice de peróxido $\left(\mathrm{meq} \mathrm{O}_{2} \cdot \mathrm{kg}^{-1}\right)$ & 20,58 & 9,71 \\
Índice de iodo $\left(\mathrm{mgL} .100 \mathrm{mg}^{-1}\right)$ & 96,31 & 92,90 \\
Índice de saponificação $\left(\mathrm{mg} \mathrm{KOH}^{-1}\right.$ ) & 184,10 & 181,68 \\
Matéria insaponificável (\%) & 1,72 & 1,60 \\
\hline
\end{tabular}

Tabela 7. Compostos presentes na fração esterólica do óleo de abacate, da variedade Margarida, em g. $100 \mathrm{~g}^{-1}$ de esteróis totais.

\begin{tabular}{lccc}
\hline \multirow{2}{*}{ Esteróis } & \multicolumn{3}{c}{ Variedades de abacate } \\
\cline { 2 - 4 } & Margarida & Fuerte & Waldin \\
\hline Colesterol & 0,3 & 1,8 & 2,3 \\
Campesterol & 6,6 & 6,3 & 4,9 \\
Stigmasterol & 1,5 & 0,8 & 1,1 \\
$\beta$-sitosterol & 71,8 & 8,7 & 83,7 \\
Delta-5-avenasterol & 7 & 1,8 & 5,8 \\
Sitostanol & 6 & - & - \\
Clerosterol & 13,4 & - & - \\
Campestanol & 0,7 & - & - \\
Outros & 2,7 & - & - \\
\hline
\end{tabular}

$\beta$-sitosterol e campesterol, com a vantagem de possuir menor quantidade de colesterol.

Importante ressaltar que alguns estudos científicos (MATVIENKO et al., 2002; TAPIERO; TOWNSEND; TEW, 2003; NATIONAL INSTITUTE OF NUTRITION, 1998) demonstram que a presença desses fitoquímicos em alimentos auxilia no controle dos níveis séricos de colesterol. A ANVISA (1999) estabeleceu uma alegação horizontal para os fitosteróis. Essa alegação permite dizer que "Os fitosteróis auxiliam na redução da absorção de colesterol. Seu consumo deve estar associado a uma dieta equilibrada e hábitos de vida saudáveis".

Na Tabela 8, estão presentes os resultados da composição em esteróis do óleo da variedade Margarida, comparados com a composição de esteróis de azeite de oliva nacional.

A ANVISA (2000) determina que o percentual de Campesterol em azeites de oliva deve ser de no máximo $4 \%$, o de Estigmasterol deve ser inferior ao de Campesterol e um mínimo de $93 \%$ para $\beta$-sitosterol e isômeros. Logo, pode-se observar que o óleo da variedade Margarida mostrou-se semelhante aos padrões estabelecidos.

Também foi determinada a quantidade de esteróis totais no óleo da variedade Margarina, e o resultado encontrado foi de $4640 \mathrm{mg} \cdot \mathrm{kg}^{-1}$. Segundo a Legislação Brasileira (ANVISA, 2000), o limite mínimo para todas as categorias de azeite é de $1000 \mathrm{mg} . \mathrm{kg}^{-1}$, ficando fora desta regra apenas os óleos obtidos por extração com solvente do bagaço e/ou caroço da azeitona que devem possuir um teor mínimo de $1800 \mathrm{mg} \cdot \mathrm{kg}^{-1}$. Com base neste limite, o óleo da variedade Margarida apresentou-se dentro do recomendado.

Segundo Grob e Lanfranchi (1989), a composição em esteróis é um importante parâmetro para auxiliar na identificação de adulteração do azeite de oliva. O Codex Alimentarius (1993) estabelece que a composição em esteróis do azeite de oliva é o resultado do somatório do $\beta$-sitosterol (93\%), campesterol $(4,0 \%)$ e colesterol $(0,5 \%)$ para os três tipos de azeite: virgem, refinado e de extração refinado.

Segundo Antoniassi et al. (1998), a adulteração de azeite de oliva virgem pela adição de óleos de sementes pode ser identificada pelo aumento dos teores de campesterol e estigmasterol e redução do teor de $\beta$-sitosterol.

Isso reforça ainda mais a possibilidade de inserir o óleo de abacate puro para uso comestível como substituto do óleo de oliva ou produzir o óleo de oliva e abacate mesclado, oferecendo ao consumidor brasileiro um produto de qualidade superior com menor custo.

O conteúdo de vitamina $\mathrm{E}$ encontrado no óleo de abacate da variedade Margarida foi de $6,04 \mathrm{mg} .100 \mathrm{~g} \mathrm{~g}^{-1}$ de óleo, sob a forma de $\alpha$-tocoferol. De acordo com a ANVISA (2005), a Ingestão 
Tabela 8. Comparação entre a composição de esteróis do óleo de abacate da variedade Margarida e a composição de esteróis do azeite de oliva.

\begin{tabular}{ccc}
\hline Esteróis & $\begin{array}{c}\text { Óleo de abacate } \\
\text { (Margarida) }\end{array}$ & $\begin{array}{c}{ }^{\star} \text { Azeite de oliva } \\
\text { extra virgem }\end{array}$ \\
\hline Campesterol (\%) & 6,6 & 2,3 \\
Estigmasterol (\%) & 1,5 & 0,7 \\
$\beta$-sitosterol (\%) & 71,80 & 96,4 \\
\hline
\end{tabular}

${ }^{*}$ Fonte: Becker (2005).

Diária Recomendada (IDR) de proteína, vitaminas e minerais para adultos e a IDR para a vitamina E é de $10 \mathrm{mg}$ de $\alpha$-tocoferol. Diante disso, conclui-se que o óleo de abacate da variedade estudada é uma boa fonte desta vitamina, pois $30 \mathrm{~mL}$ deste óleo atendem a $18 \%$ das necessidades diárias de um adulto.

Segundo a ANVISA (1998), que estabelece diretrizes para os alimentos que utilizam informação nutricional complementar, para ser considerado alimento rico ou com alto teor de uma determinada vitamina, o mesmo precisa oferecer no mínimo $15 \%$ do valor correspondente ao previsto na Tabela de Ingestão Diária Recomendada (IDR). Portanto, caso esse óleo venha ser comercializado no varejo, é possível utilizar essa alegação em sua rotulagem.

\section{Conclusões}

- A extração e refinação do óleo de abacate a partir de frutos da variedade Margarida são processos tecnicamente viáveis;

- Entre os solventes utilizados na extração, o hexano e a cetona, na proporção 1:1, apresentaram melhores resultados, tanto no rendimento quanto nas características gerais do óleo;

- Nos ensaios de neutralização, pôde-se avaliar que a melhor concentração da solução de $\mathrm{NaOH}$ foi de $30^{\circ} \mathrm{Bē}$ $\left(23,67 \mathrm{~g} \mathrm{NaOH} .100 \mathrm{~g}^{-1}\right)$, onde se obteve uma floculação mais rápida e firme, sem formação de emulsão e com boa sedimentação da borra (sabão), não afetando o rendimento do óleo neutralizado; e

- De acordo com o resultado das análises de composição de esteróis e ácidos graxos do óleo de abacate, confirma-se a possibilidade de utilizá-lo em substituição ao azeite de oliva ou como matéria-prima para a indústria alimentícia, pois suas composições nutricionais são muito semelhantes. No entanto, são necessários mais estudos para melhorar o sabor e o aroma deste óleo.

\section{Referências bibliográficas}

AMERICAN HEART ASSOCIATION. Heart and stroke statistical update. Dallas: American Heart Association, 2002.

AMERICAN OIL CHEMISTS' SOCIETY. Official and tentative methods. 3 ed. Champaign: A.O.C.S., 1983.

AMERICAN OIL CHEMISTS' SOCIETY. Official Methods and Recommended Practices of the American Oil Chemists Society. 4 ed. Champaign: A.O.C.S., 1990.
ANTONIASSI, R. et al. Avaliação das características de identidade e qualidade de amostras de azeite de oliva. Brazilian Journal of Food Technology, v. 1, n. 1, 2, p. 32- 43, 1998.

AOAC. Official Methods of Analysis of the Association of Official Analytical Chemists. 40 ed. Washington, 1984.

AOCS. Official Methods and Recommended Practices of the American Oil Chemists Society. 3. ed. Champaign, v. 1-2, 1995.

ARTZ, W. E. et al. Incorporation of corn fiber into sugar snap cookies. Cereal Chemistry, v. 67, n. 3, p. 303-305, 1990.

BRASIL. Agência Nacional de Vigilância Sanitária - ANVISA. Resolução n. 270, de 22 de setembro de 2005. Regulamento técnico para óleos vegetais, gorduras vegetais e creme vegetal. Diário Oficial da União, Brasília, 23 de setembro de 2005, p. 2134.

BRASIL. Agência Nacional de Vigilância Sanitária - ANVISA. Portarias 18 e 19, de 30 de Abril de 1999. Regulamento Técnico que estabelece as diretrizes básicas para análise e comprovação de propriedades funcionais e ou de saúde alegadas em rotulagem de alimentos. Diário Oficial da União, Brasília, 3 de maio de 1999, p. 1967.

BRASIL. Agência Nacional de Vigilância Sanitária - ANVISA. Resolução no 482, de 23 de setembro de 1999. Regulamento Técnico para Fixação de Identidade e Qualidade de Óleos e Gorduras Vegetais. Diário Oficial da União, Brasília, publicada em 20 de junho de 2000, n. 3029.

BRASIL. Agência Nacional de Vigilância Sanitária - ANVISA. Portaria SVS no 27 de 13 de janeiro de 1998. Regulamento Técnico que estabelece as diretrizes para os alimentos que utilizam informação nutricional complementar. Diário Oficial da União, Brasília, 16 de janeiro de 1998, p.1354.

BECKER, D. F. S. et al. Quantificação de fitosteróis em azeite de oliva importados e disponíveis nocomércio de Campinas utilizando cromatografia fase gasosa. Brazilian journal of food technology, v. 8, n. 3, p. 190-199, 2005.

CARDOSO, A. M.; MATTOS, I. E.; KOIFMAN, R. J. Prevalência de fatores de risco para doenças cardiovasculares na população Guaraní-Mbyá do Estado do Rio de Janeiro. Caderno de Saúde Pública, v. 17, n. 2, p. 345-354, 2001.

CODEX ALIMENTARIUS COMMISSION - FAO/WHO. Codex Alimentarius. Fats, oils and related products. $2 \mathrm{ed}$. Roma: Secretariat of the Joint FAO/WHO Food Standards Programme, 1993. v. 8, p. 133.

COMMITTEE ON DIET AND HEALTH. Diet and health implications for reducing chronic disease risk. Washington, DC: Nacional Academy Press, 1989.

CORONELLI, C. L. S.; MOURA, E. C. Hipercolesterolemia em escolares e seus fatores de risco. Revista de Saúde Pública, v. 37 , n. 1, p. 24-31, 2003.

EL-DASH, A. A.; GERMANI, R. Tecnologia de farinha mistas: uso de farinhas mistas na produção de biscoitos. 1. ed. Brasília: Empresa Brasileira de Pesquisa de Tecnologia Agroindustrial de Alimentos (EMBRAPA - SPI), 1994. 47p.

GERBER, Z. R. S.; ZIELINSKY, P. Fatores de risco de aterosclerose na infância: um estudo epidemiológico. Arquivo Brasileiro de Cardiologia, v. 69, n. 4, p. 231-236, 1997.

GROB, K.; LANFRANCHI, M. Determination of Free and Esterified Sterols and of Wax Esters in Oils and Fats by Coupled Liquid Chromatography-GasChromatography. Journal of Chromatography, v. 471, p. 397-405, 1989.

HARTMAN, L.; ESTEVES, W. Tecnologia de óleos e gorduras vegetais. São Paulo: Comércio, Ciência e Tecnologia, 1982. (Secretaria de Estado da Indústria, 13). 
JELTEMA, M. A.; ZABIK, M. E.; THIEL, L. J. Prediction of cookie quality from dietary fiber components. Cereal Chemistry, v. 60, n. 3, p. 227-230, 1983.

JORGE, P. A. R. et al. Efeito da berinjela sobre os lipídeos plasmáticos, a peroxidação lipídica e a reversão da disfunção endotelial na hipercolesterolemia experimental. Arquivo Brasileiro de Cardiologia, v. 70, n. 2, p. 87-91, 1998.

MATVIENKO, O. A. et al. A single daily dose of soybean phytosterols in ground beef decreases serum total cholesterol and LDL cholesterol in young, mildly hypercholesterolemic men. American Journal of Clinical Nutrition, v. 76, n. 1, p. 57-64, 2002.

MEDINA, J. C. Abacate: da cultura ao processamento e comercialização. Campinas: Ital, 1978.

MONTENEGRO, H. W. S. A cultura do abacateiro. São Paulo: Editora Melhoramentos, 1961.

MOURA, E. C. et al. Perfil lipídico em escolares de Campinas, SP, Brasil. Revista de Saúde Pública, v. 34, n. 5, p. 499-505, 2000
NATIONAL INSTITUTE OF NUTRITION. Functional foods and safety in the news. Tóquio, 1998. v. 13.

SOARES, S. E.; MANCINI FILHO, J.; DELLA MODESTA, R. C. Sensory detection limits of avocado oil in mixtures with olive oil. Revista Española de Ciencia y Tecnologia de Alimentos, v. 32, n. 5, p. 509-516, 1998.

TANGO, J. S.; CARVALHO, C. R.; LIMONTA, S. N. B. Caracterização física e química de frutos de abacate visando a seu potencial para extração de óleo. Revista Brasileira de Fruticultura, v. 26, n. 1, p. 17-23, 2004.

TAPIERO, H.; TOWNSEND, D. M.; TEW, K. D. Phytosterols in the prevention of human pathologies. Biomedical Pharmacothery, v. 8, n. 57 , p. 321-325, 2003.

UNITED STATE DEPARTMENT OF AGRICULTURE. Agricultural Research Service. Nutrient Database of Standard Reference. $18 \backslash$ ed. United State, 2005. 